\title{
Whole-Body Vibration in Farming: Background Document for Creating a Simplified Procedure to Determine Agricultural Tractor Vibration Comfort
}

\author{
Maurizio Cutini * (D), Massimo Brambilla and Carlo Bisaglia \\ CREA Research Centre for Engineering and Agro-Food Processing, via Milano 43, 24047 Treviglio (BG), Italy, \\ massimo.brambilla@crea.gov.it (M.B.); carlo.bisaglia@crea.gov.it (C.B.) \\ * Correspondence: maurizio.cutini@crea.gov.it; Tel.: +39-0363-49603
}

Received: 19 July 2017; Accepted: 26 September 2017; Published: 29 September 2017

\begin{abstract}
Operator exposure to high levels of whole-body vibration (WBV) presents risks to health and safety and it is reported to worsen or even cause back injuries. Work activities resulting in operator exposure to whole-body vibration have a common onset in off-road work such as farming. Despite the wide variability of agricultural surface profiles, studies have shown that with changing soil profile and tractor speed, the accelerations resulting from ground input present similar spectral trends. While on the one hand such studies confirmed that tractor WBV emission levels are very dependent upon the nature of the operation performed, on the other, irrespective of the wide range of conditions characterizing agricultural operations, they led researchers to set up a possible and realistic simplification and standardization of tractor driver comfort testing activities. The studies presented herewith indicate the usefulness, and the possibility, of developing simplified procedures to determine agricultural tractor vibration comfort. The results obtained could be used effectively to compare tractors of the same category or a given tractor when equipped with different seats, suspension, tyres, etc.
\end{abstract}

Keywords: lower back pain; safety; comfort; test track; whole-body vibration

\section{Introduction}

Agricultural tasks rank among the most hazardous occupations-according to work injury statistics, the related fatality rate is six times higher than that of all other industrial activities together and there is concern about the growing number of leisure-related farm injuries [1,2].

Occupational exposure has been recognized as one of the most important contributors to the onset of chronic diseases the outcomes of which, even if not resulting in premature mortality, can result in substantial disability, thus representing an extremely important cost from human and socio-economic perspectives [3,4]. Workers' safety issues range from proper accident prevention (resulting from the improvements to devices) to attention to the operator's welfare and comfort; this is related to microclimate as well as to exposure to physical and chemical agents $[5,6]$. Agricultural operators can also be exposed at the same time to different risk factors: for example, when running agricultural machines, workers experience physical (noise, vibrations), chemical (dust and chemical agents in the air, smoke) and biological (spores, micro-organisms and pollen which are conveyed with the dust) hazard exposure [7].

A risk factor requiring attention in agriculture is the exposure to vibration, both whole-body and hand harm. It has been pointed out that vibrations with a frequency lower than $2 \mathrm{~Hz}$ can induce minor and temporary effects like carsickness that, producing remarkable discomfort, interfere with the desired working performance while long-term exposure to vibrations ranging from 2 to $20 \mathrm{~Hz}$ can cause severe diseases such as spinal column degenerative pathologies [8-10]. Such harmful vibrations, 
when worsened by difficult working conditions (e.g., uncomfortable postures, inappropriate seats, frequent handling operations, etc.), could even lead to spinal disorders [11]. Operating hand-held olive harvesters has shown high levels of hand-arm vibrations (HAV) due to hand contact with the handle $[12,13]$. The prolonged exposure to these types of stresses could cause the so-called hand arm vibration syndrome (HAVS), which affects the various structures of the upper limb (musculoskeletal, nervous and vascular) [14-16]. The rise of these problems in both developed and less developed countries confirms that the ergonomic aspects of agriculture need adequate attention [17].

European Directive 2002/44/EC [18] defines "Whole-body vibration" (WBV) as "the mechanical vibration that, when transmitted to the whole-body, entails risks to the health and safety of workers, in particular lower-back morbidity and trauma of the spine." As far as seated operators are concerned, the ISO 5008/2002 [19] standard further specifies that WBV is the "vibration transmitted to the body as a whole through the buttocks of a seated operator." Exposure to high levels of whole-body vibration can cause or aggravate back injuries. Such risks are greatest when vibration magnitudes are high, exposure durations are/become long, frequent and regular and, furthermore, vibration includes severe shocks or jolts.

Ergonomic factors such as manual handling of loads as well as restricted or awkward postures [20] can be as important as exposure to WBV in causing back injury [21]: as a matter of fact, all these factors can separately result in the onset of back pain [22] and the risk turns out to be increased when, during WBV exposure, the operator is additionally exposed to one or more of these factors (environmental factors like temperature included).

People using agricultural machinery are likely to be exposed to the risk of vibration, therefore action to reduce workplace exposure to WBV is required for most operators who often run agricultural machinery. Manufacturers are continuously improving tractor comfort with active seats, the adoption of front suspension and on purpose designed cab suspension systems. Nevertheless, these efforts suffer from the lack of a focused approach to define tractor comfort. Studies on tractor dynamics indicate the technical possibility of filling this gap by developing a standard aimed at characterizing tractors in terms of comfort levels.

In this paper, after reviewing WBV risk analysis and the methods used for WBV assessment, we provide a different approach to WBV evaluation that introduces the possibility of setting up a simplified procedure to determine the vibration comfort of agricultural tractors.

The paper indicates the usefulness and the possibility of developing such a simplified procedure so that the outcome can be used: (1) to compare different tractors, provided that they belong to the same category; (2) the exposure resulting from varying the equipment mounted on a given tractor (seats, suspension, tyres, etc.). Such simplified testing procedures cannot, however, be considered suitable for determining operators' daily exposure to vibration in open field conditions.

\section{The Risk of Whole-Body Vibration in Farming}

\subsection{Whole-Body Vibration and Lower Back Pain}

Lower back disorders have been significantly associated with heavy machinery operating tasks because of the biological mechanisms arising from WBV exposure and wrong postures which, in turn, are related to workplace characteristics and use, like the kind of seat, operating speed, track or tyres, cab design, the amount of time spent while seated, and the task performed [23].

In particular, results of interest can be found in the work of Lings [24] who reviewed the literature of the past seven years to find out: (i) whether there is evidence in the epidemiological literature of a causal association between WBV and lower back pain (LBP); and (ii) if there is evidence in the recent literature of a dose response relationship between whole-body vibration and LBP. In his study, twenty-four original articles concerning the association between WBV and LBP were selected for use. The six reports that best fulfilled the quality criteria were predominantly in favour of a positive association between WBV and LBP. Nevertheless, evidence in favour of a dose-response association 
was weak. The author concluded that there may be an association between WBV and LBP. However, it is not possible to decide whether WBV exposure per se is capable of causing LBP, or if WBV only constitutes a risk in combination with other factors, such as prolonged sitting as well as certain work postures. All the same, the current knowledge yields sufficient reasons for reducing WBV exposure to the lowest possible level.

In one of the six abovementioned studies, a survey was carried out on 1155 tractor drivers: tractor vibration and/or incorrect posture in driving activities were identified as causing more than $80 \%$ of the interviewees to suffer from lower back disorders [25].

The findings of this epidemiological study indicate that tractor driving is significantly related to an increased risk of lower back symptoms. While checking for several potential confounders by logistic modelling, total vibration dose and awkward postures at work were found to be the most predictive occupational factors for the occurrence of LBP among the tractor drivers. Quantitative regression analysis evinced a linear effect of postural load on the increased risk of LBP, while for WBV exposure this risk was found to be proportional to the power of the estimated vibration dose.

Despite this, more epidemiological and exposure data are needed in order to improve the knowledge of the dose-effect relationship between WBV exposure and lower back troubles among professional drivers.

\subsection{Whole-Body Vibration and Professional Diseases}

It is not simple to correlate LBP with professional lower back pain diseases (LBPD) for several reasons regarding the different approaches that different countries have to defining LBPD.

With reference to the systems, criteria and diagnostic tools used to recognize LBPD, Lötters [26] aimed to develop a model for determining the work-relatedness of lower back pain for workers with these symptoms, using both personal exposure profiles for well-established risk factors and the probability of lower back pain in the event of no exposure to such factors. To provide information on the level of work-relatedness of LBP, he developed a model based on the epidemiologic information available in the literature. Clinical decision-making modelling techniques enabled the design of a tool that could help general practitioners and occupational health physicians to assess the work-relatedness of LBP for an individual worker given the worker's exposure profile to well-established risk factors. The physical risk factors included in the model were manual handling of materials, frequent bending or twisting of the trunk, and whole-body vibration exposure.

The cut-offs that were used for high exposure were approximately: lifting weights of more than $15 \mathrm{~kg}$ for $10 \%$ of worktime for the manual handling of materials; 30 degrees of bending for more than $10 \%$ of worktime for frequent bending or twisting of the trunk and, with reference to WBV, 5 years of exposure to $1 \mathrm{~ms}^{-2}$ or an equivalent vibration dose. The model was built based on the age-dependent prevalence of lower back pain for unexposed persons: the additional presence of one or more of the risk factors under examination further raised the probability of LBP. The transformation of the model into a flow chart yielded a score ranging from +3 to +5 for manual handling of materials, frequent bending or twisting of the trunk, whole-body vibration, and job dissatisfaction. The score can increase to higher values (from +5 to +7 ) in the event of estimates of high exposure to the abovementioned physical risk factors. From all these possible scores, a concomitant probability for LBP could be derived: its transposition into an etiologic fraction indicates the level of work-relatedness for lower back pain.

In another analysis carried out by Laštovková [27], epidemiological studies pointed out the existence of a statistically significant correlation between LBPD and certain types of occupational burden. This important public and economic issue has been solved in different ways across Europe. Diagnostic criteria differ substantially with respect to both verification of the workload and the range of diagnoses of diseases accepted, and not all EU countries currently include LBPD caused by overload and/or WBV in their list of occupational diseases. Those who take it into account use different systems, criteria and diagnoses to recognize LBPD as an occupational disease. On the one hand, in 13 out of the 23 studied countries, LBPD caused by overload can be recognized as occupational provided that 
the diagnosis is sufficiently proven, exposure criteria and/or listed occupation are satisfied and the duration of exposure is confirmed (Belgium, Denmark, France, Germany, Hungary, Italy, Lithuania, Macedonia, the Netherlands, Romania, Slovakia, Sweden and Switzerland). On the other, 14 countries recognize LBPD arising from vibrations as an occupational disease. Despite this, 8 countries do not accept LBPD as an occupational disease unless it is the outcome of an injury at work.

Specific criteria to evaluate the occupational exposure of patients with LBPD have been established in Belgium, Denmark, France, Germany, Lithuania, Macedonia, the Netherlands and Slovakia. In other countries, the evaluation is made on an individual basis. Most of these countries use an individual evaluation of the patient's disorder and related work overload as assessed by medical, hygienic and ergonomics specialists. One country (Germany) uses computer models, while others (the Netherlands, Slovakia) rely on the use of mathematical models aimed at individually assessing the relationship between occupational workload and LBPD and their causality for an affected worker. The Belgian system, which was enacted in 2004 and in which LBPD is recognized as an occupational disease, both due to overload and whole-body vibrations, was inspired by the German model. In Macedonia, LBPD is only acknowledged if it is the outcome of excessive strain by muscles, tendons and their attachments.

In the Netherlands, since 2005, a rather different system based on the results of Lötters [26] has been used to evaluate the presence of a causal link between working operations and LBP in the event of non-specific lower back pain. As previously described, this probability model is designed as a three-step plan. First, it makes the right diagnosis, second, it evaluates the work-relatedness of the risk factors (exposure to lifting and carrying, bending of the trunk and whole-body vibration), while the last step consists of totting up the scores arising from the exposure to each of the three risk factors: these result in the total score for work-relatedness probability. Recently, again in the Netherlands, a criteria document was also developed which aims to assess whether lumbar herniated disc disease (lumbosacral radicular syndrome) can be classified as an occupational disease. The work-relatedness of lumbar herniated disc disease can be recognized as an occupational disease if the worker exposure is characterized by more than 10 years of physically demanding work (daily lifting and carrying of loads of at least $5 \mathrm{~kg}$ for, on average, $2 \mathrm{~h}$ or 25 times per day, including bending of the trunk more than $20^{\circ}$ for at least one hour a day). The assumption that driving a vehicle by itself is a risk factor for lumbar herniated disc disease was not supported in this review.

In Switzerland, the etiologic contribution of occupation is estimated individually by physicians specialized in occupational medicine. For overdose-induced LBPD, the causality of the occupational workload has to be $75 \%$ or more, provided that diagnosis is confirmed by imaging methods. In the event of vibration-induced damages, an etiologic contribution of the occupation of $50 \%$ or more is sufficient.

France uses item no. 98 of the French list of occupational diseases related to LBPD (lifting heavy weights), which was introduced in 1999 [15]. To benefit from the work-relatedness presumption and allow the "automatic" recognition of LBPD as occupational in a patient that has been working in a defined occupation/branch of industry, he/she has to meet three of the following conditions: (i) being affected by sciatica/radiculalgia and having a corresponding disc hernia; (ii) having been exposed to lifting heavy weights for at least 5 years; (iii) a less than six-month interval between the last exposure and the diagnosis.

In practice, the assessment of occupational overload and its contribution to the onset of LBPD as well as its inclusion in the compensation system are important for several reasons. Firstly, it may be considered essentially preventable. Secondly, cases with a significant contribution of occupational etiology may be viewed as occupational diseases for which compensation may be claimed, as is the case in many European countries. Furthermore, including LBPD in the list of occupational diseases or another system of compensation may be viewed as a preventive measure as it increases the visibility of this problem not only for the workers, but especially for the employers [27]. These conclusions are also reported in the findings of Hulshof [28], who indicated that significant differences exist in the established and applied criteria for WBV-related injury in four EU countries (the Netherlands, Belgium, 
France and Germany) where this injury is currently established as an occupational disease. Whereas "Mrs Robinson" would get recognition and compensation in one or two countries, she would be rejected in the other ones. Furthermore, the large variance in the annual incidence of this occupational disease in countries with comparable WBV exposure distribution in the working population confirms the disparity between them. This disparity, on the one hand, is partly due to differences in the occupational disease systems in general, but on the other it is also caused by the differences in the specific criteria considered for the evaluation of this occupational disease [28].

\subsection{The Risks Arising from Physical Agents: Directive 2002/44}

Directive 2002/44/EC (European Community) [18], on the exposure of workers to the risks arising from physical agents (vibration), seeks to introduce, at the Community level, minimum protection requirements for workers when they are exposed to risks arising from vibration in the course of their work. Directive 2002/44/EC sets out 'exposure action values' (EAVs) and 'exposure limit values' (ELVs). The EAV is the amount of daily exposure to whole-body vibration above which you are required to take action to reduce risk: it is set at a daily exposure of $0.5 \mathrm{~ms}^{-2} \mathrm{~A}(8)$. Whole-body vibration risks are low for exposures around the action value and only simple countermeasures are usually necessary in these circumstances.

The ELV is the maximum amount of vibration an employee may be exposed to on any single day: it is set at a daily exposure of $1.15 \mathrm{~ms}^{-2} \mathrm{~A}(8)$. Operators of some off-road machines and vehicles may exceed the limit value, but this depends on the task, vehicle speed, ground conditions, driver skill and duration of the operation. Moreover, the ELV also: (i) specifies employers' obligations with regard to risk assessment and determination; (ii) sets out the measures to be taken to reduce or avoid exposure and (iii) details how to provide information and training for workers. Any employer who intends to carry out work involving risks arising from exposure to vibration must implement a series of protection measures before and during the work. The Directive also requires EU Member States to put in place a suitable system for monitoring the health of workers exposed to risks arising from vibrations. When carrying out the risk assessment, employers must pay particular attention to the following:

- the level, type and duration of exposure, including any exposure to intermittent vibration or repeated shocks;

- the exposure limit values and the exposure action values;

- $\quad$ any effects concerning the health and safety of workers at particularly sensitive risk;

- any indirect effects on worker safety resulting from interactions between mechanical vibration and the workplace or other work equipment;

- information provided by the work equipment manufacturers in accordance with the relevant Community Directives;

- the existence of replacement equipment designed to reduce the levels of exposure to mechanical vibration;

- the extension of exposure to whole-body vibration beyond normal working hours under the employer's responsibility;

- $\quad$ specific working conditions such as low temperatures;

- appropriate information obtained from health surveillance, including published information, as far as possible.

Risks arising from exposure to mechanical vibration must be eliminated at their source or reduced to a minimum by taking account of technical progress and the availability of measures that enable control of the risk at source. The reduction of such risks must be based on the general principles of prevention. On the basis of the risk assessment, once the exposure action value is exceeded, employers must establish and implement a programme of technical and/or organizational measures aimed at reducing exposure to mechanical vibration and attendant risks to a minimum. In particular, they must take into account: 
- other working methods that require less exposure to mechanical vibration;

- the choice of appropriate work equipment of an appropriate ergonomic design and, in line with the work to be done, producing the least possible vibration;

- the provision of auxiliary equipment that reduces the risk of injuries caused by vibration, such as seats that effectively reduce whole-body vibration and handles that reduce the vibration transmitted to the hand-arm system;

- appropriate maintenance programmes for work equipment, the workplace and workplace systems;

- the design and layout of workplaces and work stations;

- adequate information and training to instruct workers to use work equipment correctly and safely in order to reduce their exposure to mechanical vibration to a minimum;

- limitation of the duration and intensity of the exposure;

- appropriate work schedules with adequate rest periods;

- the provision of clothing to protect exposed workers from cold and damp.

\subsection{Current Results of In-Field Measurements}

Several studies reporting the results of measuring tractor operator WBV can be retrieved in the literature. These data are always quite similar and confirm that people using agricultural machinery are likely to undergo vibration exposure above the EAV. In some cases, action may be required to keep workers' exposure below the ELV.

\subsubsection{HSE (Health and Safety Executive, UK) Information Sheet No. 20, Revision 2}

Among the published works, we can note HSE information sheet No. 20, Rev. 2 [29], "Whole-body vibration in agriculture", which groups agricultural tasks according to likely exposure:

Group 1: WBV unlikely to be a risk. For these tasks, the estimated exposure is likely to be below the EAV with no significant shocks. The adoption of low-cost vibration reduction measures and the management of WBV will reduce the likelihood and the persistence of back pain. It is unusual for machinery-related tasks in agriculture to fall into this category. Even if machinery is shared among a large workforce and exposure durations are short enough to maintain exposures below the EAV, it is highly likely that there will be some exposure to significant shocks.

Group 2: You must manage exposure to WBV. This refers to tasks according to which exposures are likely to exceed the EAV on at least some days, but shocks are expected to be small. These may be:

(i) combining, hedging and ditching;

(ii) self-propelled foragers;

(iii) duties not otherwise listed requiring use of a power take-off shaft.

Here, the risk of back pain from WBV is likely to be low and back pain is more likely to be caused by other factors. Low-cost vibration reduction and management measures must be put in place (costly or difficult measures are unlikely to be reasonably practicable).

Group 3: WBV is a likely cause of back pain. In this case exposures are likely to be much higher than the EAV and/or contain large shocks. Here effective engineering and management controls must be put in place. Health monitoring is recommended to confirm that the risk from WBV is under control. These activities are:

(i) Baling, drilling, foraging, spraying, ploughing, harrowing;

(ii) Primary cultivation (up to $5.5 \mathrm{~h}$ );

(iii) Mowing (up to $8 \mathrm{~h}$ );

(iv) Tedding (up to $5 \mathrm{~h}$ );

(v) Transport using unsuspended tractors (up to $4.5 \mathrm{~h}$ );

(vi) Transport using tractors with suspended cab or chassis (up to $7 \mathrm{~h}$ ); 
(vii) Driving an ATV (all-terrain vehicle/quad bike) up to $5.5 \mathrm{~h}$.

Group 4: You must restrict exposure to WBV. When dealing with these tasks the ELV must be taken as the reference and people's exposure to WBV should be restricted accordingly. Such restrictions must be applied to the following tasks:

(i) Primary cultivation (over $5.5 \mathrm{~h}$ );

(ii) Mowing (over $8 \mathrm{~h}$ );

(iii) Tedding (over $5 \mathrm{~h}$ );

(iv) Transport using unsuspended tractors (over $4.5 \mathrm{~h}$ );

(v) Transport using tractors with suspended cab or chassis (over $7 \mathrm{~h}$ );

(vi) Driving an ATV (over 5.5 h).

\subsubsection{The ENAMA Technical Document}

The ENAMA (Italian Board for Agricultural Mechanization) technical document [30] on the problem of agricultural machinery vibration reports the mean values of the vertical acceleration, weighted in frequency, of the measurement at the seat of 77 tractors together with the relevant time of exposure characterizing the EAV (Table 1).

Table 1. Mean values of the acceleration, weighted in frequency, of the measurement at the tractor seat with the relevant time of exposure; EAV: Exposure action values.

\begin{tabular}{cccc}
\hline No. & Task & Mean Value $\mathbf{~ m s}^{-\mathbf{2}}$ & Exposure Time EAV (h-min) \\
\hline 1 & Forage Baling & 0.50 & $8-00$ \\
2 & Harvesting & 0.45 & $9-53$ \\
3 & Maintenance of hedgerows and ditches & 0.42 & $11-20$ \\
4 & Eradication and harvesting of beet & 0.70 & $4-05$ \\
5 & Fertilizer spreading & 1.30 & $1-11$ \\
6 & Tillage with disk harrow & 1.20 & $1-23$ \\
7 & Mowing & 1.00 & $2-00$ \\
8 & Ploughing & 1.01 & $1-58$ \\
9 & Rotary harrow & 1.70 & $0-42$ \\
10 & Loading and unloading & 1.20 & $1-23$ \\
11 & Windrowing & 1.00 & $2-00$ \\
12 & Rolling & 0.60 & $5-33$ \\
13 & Transport with trailer & 0.93 & $2-19$ \\
14 & Manure spreading & 0.60 & $5-33$ \\
15 & Spraying & 1.15 & $1-31$ \\
16 & Rear-mounted backhoe & 0.74 & $3-39$ \\
17 & Wood hauling & 1.14 & $1-32$ \\
\hline
\end{tabular}

\subsubsection{CEMA Practical User's Guide}

The European Agricultural Machinery Association (CEMA) published the leaflet: "Whole-body Vibration in Agriculture, CEMA Practical User's Guide" [31]. It contains notes on good practice and can be regarded as a guideline. It is based on the HSE information sheet "WBV in Agriculture".

\subsubsection{EU WBV Good Practice Guide}

The EU document, "The guide to good practice on Whole-Body Vibration, non-binding guide to good practice with a view to implementation of Directive 2002/44/EC (European Community) on the minimum health and safety requirements regarding the exposure of workers to the risks arising from physical agents (vibrations)" [32] reports examples of vibration magnitudes for common machines (Figure 1). 


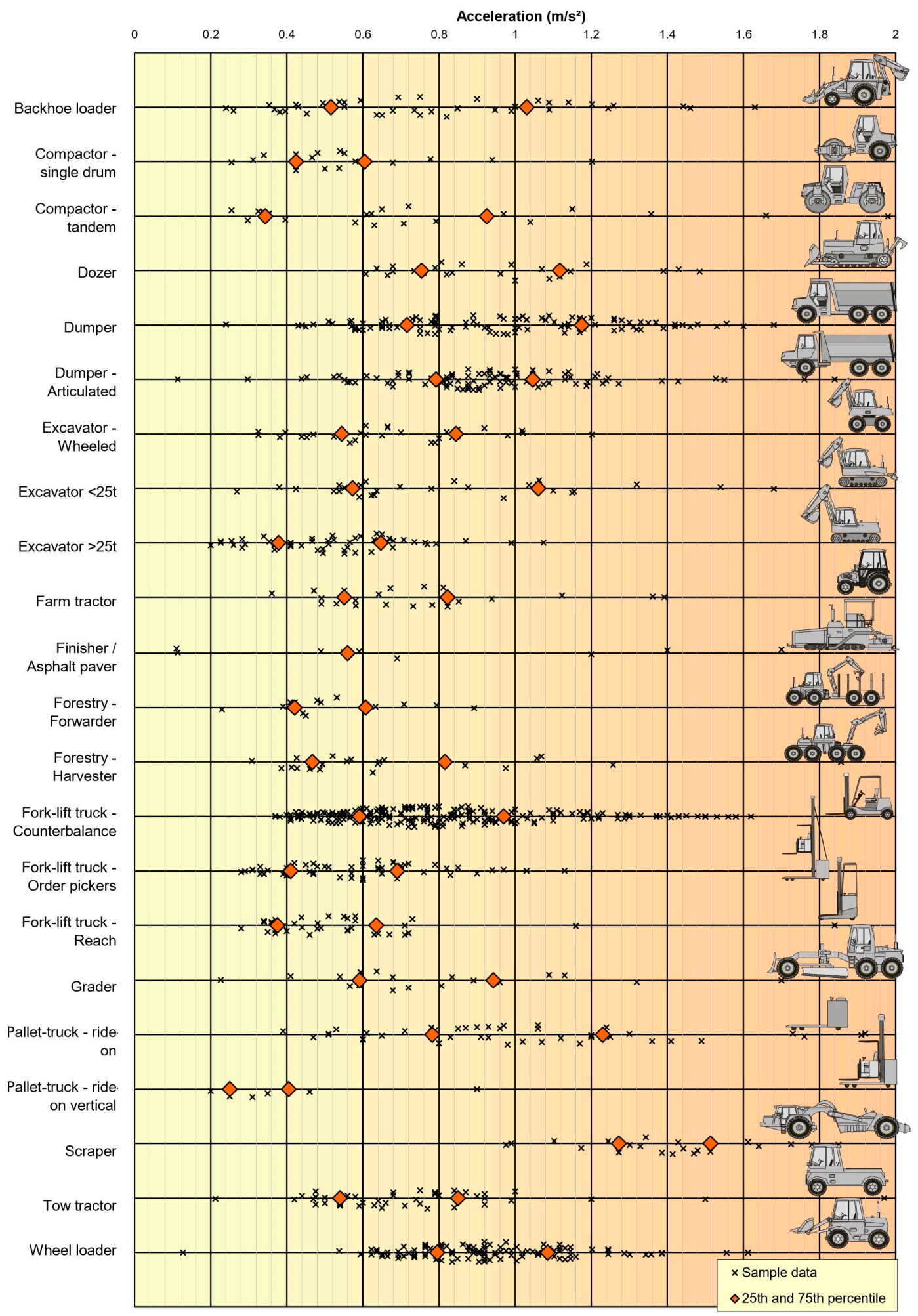

Figure 1. Examples of vibration magnitudes for common machines. Sample data based on workplace vibration measurements of the highest axis vibration values by the Institut national de recherche et de sécurité (INRS) (with the assistance of CRAM (Caisse régionale d'assurance maladie) and Prevencem), HSL (Health and Safety Laboratory) and the RMS Vibration Test Laboratory between 1997 and 2005 (EU, Guide to Good Practice on Whole-Body Vibration, 2006) [32]. 
The displayed data are based on workplace vibration measurements of the highest axis vibration values carried out by the INRS (Institut national de recherche et de sécurité) with the assistance of CRAM (Caisse régionale d'assurance maladie) and Prevencem, HSL (Health and Safety Laboratory) and the RMS Vibration Test Laboratory between 1997 and 2005. These data are for illustration only and may not be representative of machine use in all circumstances. The 25th and 75th percentile points show the vibration magnitude that $25 \%$ or $75 \%$ of samples are equal to or below. It is possible to see how the agricultural tractor data comply with the HSE and ENAMA document.

\section{Test Methods for Measuring Vibration}

Frequency represents the number of times per second the vibrating body moves back and forth. It is expressed as a value in cycles per second, more usually known as hertz (Hz).

For WBV, the frequencies thought to be important range from $0.5 \mathrm{~Hz}$ to $80 \mathrm{~Hz}$. However, because the risk of damage is not equal at all frequencies, a frequency-weighting is used to represent the likelihood of damage arising from different frequencies. As a result, the weighted acceleration decreases when the frequency increases. A brief description of the objective measures used (AAP (Average Absorbed Power); BS (British Standard) 6841, VDI (Verein Deutscher Ingenieure) 2057, NASA (National Auronautics and Space Administration) 2299 and ISO (International Standard Organization) 2631-1997) follows [33].

\subsection{Average Absorbed Power (AAP)}

Average Absorbed Power (AAP) was developed by the US Army Tank-Automotive Command in 1966. Studies have shown that the human body behaves in an elastic fashion. Under vibration, the body's elasticity produces restoring forces that are related to displacement. This process continues until the energy imparted is dissipated or removed. The time rate of energy absorption is referred to as the absorbed power. The absorbed power can be computed in the frequency domain as well as in the time domain. The frequency domain ranges between 1 and $80 \mathrm{~Hz}$ and below $1 \mathrm{~Hz}$ the method is considered not successful. The AP (Absorbed Power) weighting curve strongly emphasizes the visceral resonance occurring at around $4-5 \mathrm{~Hz}$, presumably because most energy is absorbed by these softer tissues.

\subsection{The BS 6841 Standard}

The BS 6841 standard [34] considers a frequency range of $0.5-80 \mathrm{~Hz}$ while introducing a new procedure based on the concept of Vibration Dose Value (VDV) instead of time dependency curves. The frequency weighting for z-axis seat vibration is modified to be in closer agreement with the results of experimental research. For each axis, a component ride value can be determined as well as an overall ride value. At first the acceleration samples are weighted using different weight functions for different directions. As for ride comfort, the root mean square (RMS) value of the weighted signal is determined as well.

\subsection{The VDI 2057 Standard}

In 1963 the Society of German Engineers (VDI) published the first VDI 2057 standard [35]. In principle, the VDI standard defines a calculated ride comfort index (K-factor) that is compared with a subjective table to determine the ride as subjectively experienced by humans. In 1979 the VDI standard adopted the ISO 2631-1978 tolerance curves, nevertheless it kept the K-factor for the subjective comparison of human-perceived sensations. The acceleration data is converted into the frequency domain using a fast Fourier transform (FFT) from which the RMS values are determined. This results in single values at the centre frequencies. The RMS acceleration is weighted and K-values are determined for the $\mathrm{z}$-direction. The weighted signal is then plotted against limit curves. These are in principle the same as the ISO 2631-1985 standard limit curves. The frequency bandwidth ranges between 1 and $80 \mathrm{~Hz}$. 


\subsection{The NASA 2299}

This Ride Comfort standard belongs to the group of measurements that occur the least. The NASA 2299 [36] standard weights RMS acceleration values with empirically gathered weighting factors. It is defined for five degrees of freedom: vertical, lateral, longitudinal, roll and pitch. This standard does not specify accelerometer location and placement to measure the degrees of freedom and this is in contrast to the well-defined location of origins recommended by the ISO 2631 standard. One can measure as many as all five accelerations or as few as one prior to calculating Ride Comfort. The applicable frequency range for the NASA 2299 standard ranges from 0.5 to $30.0 \mathrm{~Hz}$.

\subsection{The ISO 2631-1997}

The ISO 2631-1:1997 International Standard ("Mechanical Vibration and Shock-Evaluation of Human Exposure to Whole-body Vibration-Part 1: General Requirements") [37] defines the means for evaluating periodic, random and transient vibration with respect to human responses: health, comfort, perception and motion sickness.

The RMS method continues to be the basis method for the ISO 2631-1:1997. In principle, the methodology and calculations of the standard are the same as the BS 6841 standard. The main difference between the BS 6841 standard and this one is that the vertical weighting $W_{k}$ (resulting from intensive laboratory studies) replaces $\mathrm{W}_{\mathrm{b}}$.

The ISO standard specifies the direction and location of the measurements, the equipment to be used, the duration of the measurements and the frequency weighting, as well as the measurement assessment methods and the evaluation of weighted root-mean-square acceleration. The effect of frequency is reflected in frequency weightings labelled $W_{k}, W_{d}, W_{f}, W_{c}, W_{e}$ and $W_{j}$ and different frequency weightings are required for all different axes of the body. The different sensitivity of the body to vibration in each axis is accounted for by multiplying factors. The frequency-weighted acceleration (expressed as $\mathrm{m} / \mathrm{s}^{2}$ ) is multiplied by the weighting factor before its effect is assessed. For vertical seat vibration (z-axis), the acceleration weighting $\mathrm{W}_{\mathrm{k}}$ has the greatest sensitivity in the range $4-13 \mathrm{~Hz}$. For horizontal seat vibration ( $x$ - and $y$-axes), the acceleration weighting $\mathrm{W}_{\mathrm{d}}$ has the greatest sensitivity in the range $0.5-2 \mathrm{~Hz}$.

In the motion sickness assessment, the weightings $W_{k}, W_{d}, W_{c}, W_{e}$ and $W_{j}$ are used in the frequency range $0.5-80 \mathrm{~Hz}$, whereas the $W_{\mathrm{f}}$ weighting is used in the $0.1-0.5 \mathrm{~Hz}$ range.

The standard requires the evaluation to include measurement of the weighted root-mean-square (RMS) acceleration. This is expressed in metres per second squared $\left(\mathrm{ms}^{-2}\right)$ for translational vibration and vibration assessment, Equation (1), requires the calculation of the weighted and gained root-mean-square (RMS) acceleration $\left(a_{v i}\right)$ along the three axes $(i=x, y, z)$ :

$$
a_{v i}=k_{i(x, y, z)} \sqrt{\sum_{i=1}^{n}\left(W_{i} \cdot a_{i}\right)^{2}}
$$

where:

- $\quad k_{i(x, y, z)}$ is a multiplying factor (dimensionless), set at 1.4 for the $\mathrm{x}$ - and $\mathrm{y}$-axes and at 1 for the $\mathrm{z}$-axis

- $W_{i}$ is a dimensionless weighting factor given by the standard itself

- $a_{i}$ is the acceleration acquired at the seat $\left(\mathrm{ms}^{-2}\right)$.

The calculated $a_{v i}$ were subsequently used to define WBV risk conditions according to European Directive 2002/44/CEE (EC, 2002)

\subsection{The Situation in the USA}

In the USA, the three most commonly referenced voluntary WBV standards are those of the American National Standards Institute (ANSI), American Conference of Governmental Industrial Hygienists (ACGIH) and ISO. In 1979 the ANSI originally published American National Standard 
S3.18, which was almost identical to ISO 2631 and at a later date released the ANSI S3.18-2002 ISO 2631-1-1997, an adaptation of the most recent ISO standard. WBV exposure limits published by the ACGIH are based upon the ISO standard. Neither the National Institute for Occupational Safety and Health (NIOSH) nor the Occupational Safety and Health Administration (OSHA) has issued WBV standards [38].

\section{State of the Art and Possible Improvements Aimed at Reducing WBV Exposure in Farming}

The European legislation sets out the basic rules based on risk assessment and the actions to be undertaken to reduce the risk. The issue of evaluating WBV for tractor drivers involves several different themes and, consequently, requires different approaches and methods.

Considering the requirements of Directive 2002/44/EC [18], the need for WBV measurement can be summarized in the following steps:

1. Risk assessment carried out by employers: in this way vibration exposure is evaluated either with direct measurement in operating conditions representative of daily working, or by considering the data from the database proposed by the national authority on safety [39].

2. Implementation of appropriate actions to reduce the risk of mechanical vibration exposure: this can be carried out in different ways (e.g., by choosing work equipment which includes the least possible vibration), but there is currently no reference data characterizing tractors' vibrational comfort.

Table 2 reports some examples of the main topics that must be considered.

Table 2. Main topics regarding Whole-Body Vibration (WBV) risk.

\begin{tabular}{cl}
\hline \multicolumn{1}{c}{ Aim } & \multicolumn{1}{c}{ Task } \\
\hline \multirow{3}{*}{ Risk assessment } & $\begin{array}{l}\text { Evaluate the level, type and duration of exposure } \\
\text { Verify the exposure limit values and the exposure action values }\end{array}$ \\
\cline { 2 - 2 } & $\begin{array}{l}\text { Adopt information provided by the work equipment manufacturers } \\
\text { Verify the existence of replacement equipment designed to reduce the levels } \\
\text { of exposure }\end{array}$ \\
\hline \multirow{2}{*}{$\begin{array}{c}\text { Reduction of the } \\
\text { risk of mechanical } \\
\text { vibration exposure }\end{array}$} & $\begin{array}{l}\text { Adopt other working methods that require less exposure to } \\
\text { mechanical vibration }\end{array}$ \\
\cline { 2 - 2 } & \begin{tabular}{l} 
Choose appropriate work equipment producing the least possible vibration \\
\cline { 2 - 2 }
\end{tabular} \\
\hline
\end{tabular}

It is evident that the effort made by manufacturers to develop solutions to improve tractor comfort has to be properly assessed. Indeed, for several years tyres and seats have been the main mechanical vibration mitigation devices and the studies carried out on off-road and industrial vehicles have focused on tyre properties, dumping systems, and their interaction [40-44]: the development of devices mitigating vibration transmission to drivers [45-47] is currently a challenge both for manufacturers and research institutes.

Studies to quantify WBV emission and estimated exposure levels upon a range of agricultural tractors have been carried out in controlled conditions [48,49] while performing the following tasks:

- $\quad$ traversing ISO ride vibration test tracks;

- performing selected agricultural operations;

- performing identical tasks during 'on-farm' use;

- transport on paved minor roads;

- transport on focused and dedicated terrain or stony tracks. 
Tractor WBV emission levels were found to be very dependent upon the nature of the operation performed. Apart from the experiences carried out on ISO 5008, other tests found in the literature that evaluate technical solutions may not result in repeatable outcomes given the changes that dedicated tracks as well as the roads used undergo in time. The approach used to elastically characterize the tractor on a standard test track and to correlate it with some in-field operations is also very interesting [50]. But, to date, the value declared by manufacturers only refers to seat performance: indeed, with reference to agricultural tractors, there is such a wide range of data on WBV that it is impossible to presume that a single piece of data can be taken as a reference or consider the so-called worst-case scenario (as happens with noise tests) a viable solution. One step forward can be represented by the approach contained in the EN (European Norm) 13059:2002+A1:2008 (E) standard [51] that provides manufacturers with a mean value in compliance with the essential safety requirements of the Machinery Directive and associated EFTA (European Free Trade Association) regulations. It allows the comparison of industrial trucks of the same category or a given truck in different configurations (equipped with different seats, tyres, etc.). However, this standard cannot be used to assess the daily exposure of the operator to vibration in field conditions. For such a goal, the development of a simplified testing methodology must set out to define:

- a standard test track;

- a comfort index;

- the machine operating conditions.

\section{Background for a Simplified Procedure to Determine Agricultural Tractor Vibration Comfort}

\subsection{On the Definition of the Standard Test Track}

In order to tackle the first issue (defining a standard test track), the effect of soil profile on the tractor dynamics shall be analysed first.

\subsubsection{Effect of Soil Profile on Tractor Dynamics: Theoretical Considerations}

Terrain irregularity and vehicle forward speed are the most important sources of vibrations for tractors $[49,50,52]$. Increasing knowledge on terrain irregularity characteristics could improve the design of solutions for greater operator comfort. At the moment, while the ISO 8608:1995 standard [53] sets out the method to report the vertical accelerations arising from surface profiles, pointing to connections between profile roughness and mechanical failure as well as operator discomfort [53-55], it does not lay down any straightforward surface profile measurement methods or instruments, confirming the difficulties in making such measurements properly [56,57]. As a matter of fact, the methods to perform surface profile measurements can be direct or indirect:

- direct surface profile measuring methods (e.g., using optical technology) do not have the required precision or repeatability as they do not account for the surface profile deformations the machine itself induces [58]. Indeed, the ISO 8608 standard recommends taking care when making off-road measurements in the event of both soft surfaces (flattened and filtered by wheels going forward) and hard ones (because of the filtering effect of the wheel envelope);

- with reference to indirect profile measurements, one protocol provides for the adoption of a two-step procedure for performing vertical acceleration acquisition: the tractor must have previously been run on different surfaces (with the machine in operating conditions) to acquire the accelerations the machine is subjected to; afterwards test bench replication (by a deconvolution method) of the previously acquired accelerations is performed until the exact reproduction of the acquired solicitations is achieved $[59,60]$.

An experiment carried out with the latter method [61] defined the unevenness of four different surfaces (both in the time and frequency domains): despite the wide variability of agricultural surface profiles, it pointed out which features, among soil characteristics and tractor settings (i.e., ballast or 
tyre pressure), could significantly affect vehicle dynamics and WBV. According to this experiment, results have shown that by changing soil profile and tractor speed, the accelerations resulting from ground input present similar spectral trends, which were found to be relevant at frequencies of less than $4 \mathrm{~Hz}$. This result has been also validated by research carried out by running an agricultural tractor in four setting conditions and at four different forward speeds on an ISO 5008 standard test track [62]. Further investigations $[63,64]$ that considered different tractors and agricultural operations confirmed the possibility of defining a standard trend of soil solicitations. It follows that, as far as agricultural tractors are concerned, it is the vertical acceleration tractors undergo that excites their elastic components (i.e., tyres, cab, rubber mountings, etc.) and that, in turn, determines vehicle dynamics in terms of frequency.

To better understand this, the physics of tyre response to road unevenness must be considered, in particular the solicitation the elastic part the vehicle undergoes when the vehicle passes at constant speed over a cleat whose length is much smaller than the contact length therefore resulting in changes in the tyre rolling radius. According to Pacejka [40] and Jianmin [65], four main factors need to be taken into account:

- tyre envelopment properties (variations occurring in vertical and longitudinal forces, as well as in the angular velocity of the wheel);

- effective road plane (the effective height and slope of a short trapezoidal cleat is approximated at the axle by a half sine wave);

- effective rolling radius when rolling over a cleat (increment in normal load, local forward slope, local forward curvature);

- the fact that the measured response is purely vertical while on the test track there is a sum of vertical and longitudinal components.

As a matter of fact, the displacement recorded at the hub of the rolling tyre, both because of the rolling and radial deflection that occurs (as a consequence of the passage over the cleat), is ascribable to a sine wave (Figure 2). Hence, the response of the hub acceleration to the effect of the cleat results in a sine function as well, characterized by the same resonance frequency as the tyre.

It can be deduced that, even though forward speed and cleat height characterize the hub amplitude response, the vehicle response is determined by the elastic properties of its components, irrespective of forward speed or the randomness of the test track profile. In the same way, it is the response of the tyres and seat to the bump that mainly affects operator comfort.

It is therefore possible to suppose that specific standard testing should aim to provide an input force that, by exciting the main frequencies of the vehicle, is representative of the main frequencies affecting operator comfort during ordinary use.

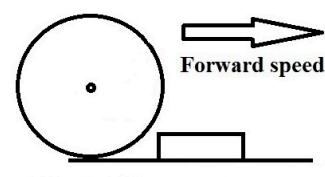

Elastic tire

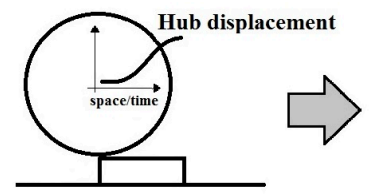

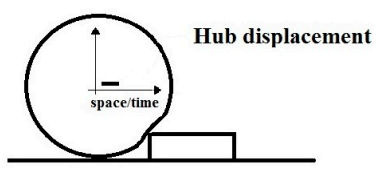

Vertical hub displacement

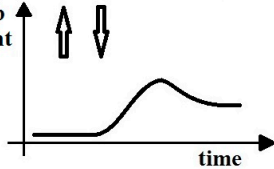

Figure 2. Diagram of the sinusoidal response of a tyre to a square input.

As a result, vertical tractor dynamics, as well as comfort and material resistance testing activities, can be greatly simplified and standardized so that elaborate test tracks can be avoided. Neither tests in the laboratory nor in the open field required the tractor to run on several test tracks, providing a 
variety of vertical solicitations, as it was sufficient to develop one rough test surface to be run at such a forward speed as to solicit the elastic parts of the tractor [66].

\subsubsection{State of the Art of the Standard Test Tracks for WBV Assessment}

With the aim of standardizing testing activity, the International Standards Organization (ISO) issued the ISO 5008:2002 standard: "Agricultural wheeled tractors and field machinery-Measurement of whole-body vibration of the operator." The purpose of this provision is to specify the instruments, measurement procedures, measurement site characteristics and frequency weighting that allow the WBV intensity of agricultural wheeled tractors and field machinery to be assessed and reported with acceptable precision. This provision defines two standard test tracks together with the relevant operating conditions. These standard test tracks are $100 \mathrm{~m}$ (smooth track, Figure 3) and $35 \mathrm{~m}$ long, composed of two different parallel, non-deformable lanes (left and right) made of wooden beams ( $80 \mathrm{~mm}$ wide and with $80 \mathrm{~mm}$ spacing in the smooth track, without spaces in the $35 \mathrm{~m}$ track) of a different standardized height to induce vibrations. EN 13059:2002 [51] sets out a method for measuring the vibration emission transmitted to the whole-body of operators of industrial trucks: it satisfies the requirements of the Machinery Directive but, as aforementioned, it cannot be used to determine the daily exposure of the operator to vibration in field conditions. With regard to industrial trucks, three predominant operating modes are considered (travelling, lifting and engine idling) and, of these, only travelling exposes the driver to significant WBV. Hence, vehicle testing is specifically based on the travelling operating mode. It consists of running the vehicle at $10 \mathrm{~km} / \mathrm{h}$ on a $25 \mathrm{~m}$-long track with two square obstacles whose height is related to the mean wheel diameter (Figure 4).

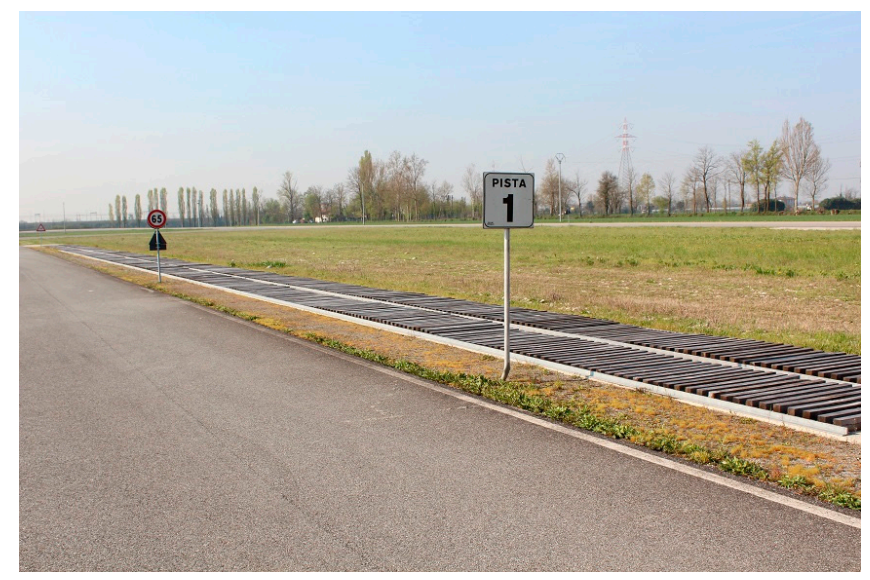

Figure 3. The International Standards Organization (ISO) 5008 100m smooth test track.

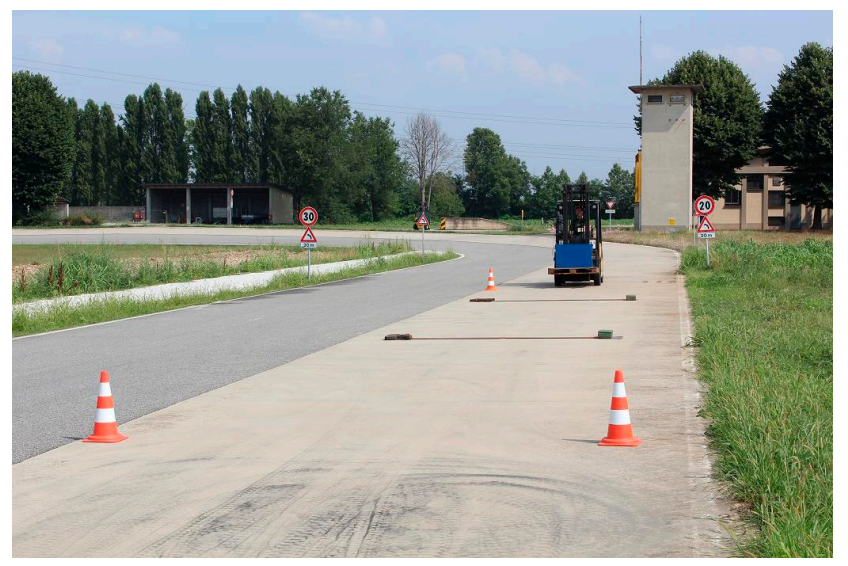

Figure 4. The $25 \mathrm{~m}$ test track defined in the EN 13059. 
This approach complies with the following requirements of Directive 2002/44:

- information provided by the work equipment manufacturers in accordance with the relevant Community Directives;

- the existence of replacement equipment designed to reduce the levels of exposure to mechanical vibration;

Transferring this methodology from industrial machines to tractors still leaves some issues open, such as measurement of the exposure along three axes (longitudinal, lateral and vertical) [67].

\subsubsection{Developing a Simplified Test Track}

Once the effect of forward speed and cleat height on hub amplitude response has been assessed-and in light of the fact that only a small range of frequencies significantly affect operator comfort given the filtering/amplification effect that different combinations of tyres and speed have on tractor response- the square prism shape of the cleat recommended by Ente Nazionale Italiano di Unificazione (UNI) 13059 [51] cannot be deemed appropriate. On the contrary, the solicitation arising from running the vehicle on ramps seems to be the most promising. A first attempt to validate this hypothesis resulted in the development of three test tracks [68], one for each axis of solicitation $(x, y, z)$, made of specifically designed ramps. Figure 5 shows the ramps developed for the $\mathrm{z}$ axis test track (1000 mm long and $50 \mathrm{~mm}$ high), whose solicitations on a tractor run at $8 \mathrm{~km} \mathrm{~h}^{-1}$ (Figure 5) were compared with those resulting from running the same tractor on field test tracks and an ISO 5008 test track.

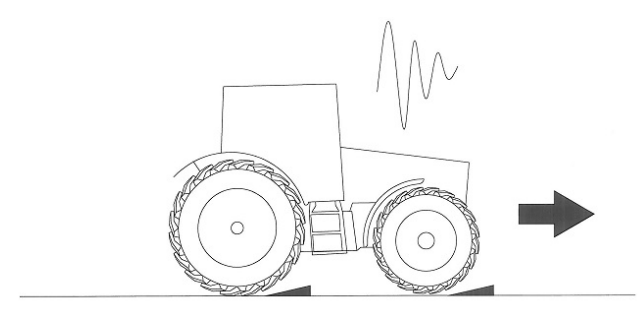

(a)

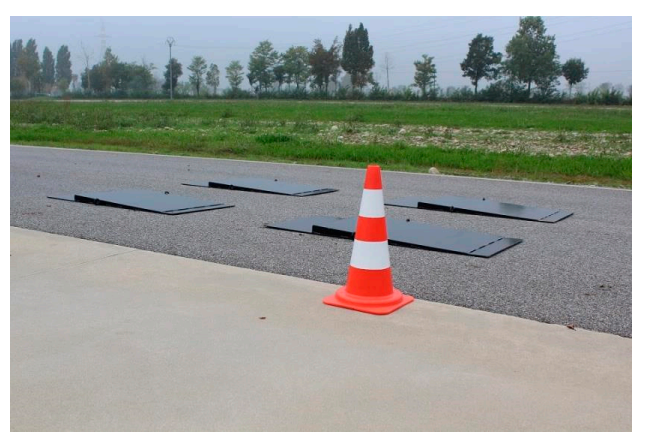

(b)

Figure 5. The simplified test layout (a) and the ramps specially developed (b) for evaluating vertical tractor comfort.

As previously mentioned, since the comfort values of each channel $(\mathrm{x}, \mathrm{y}, \mathrm{z})$ are defined by a restricted range of frequencies, which-on all the considered tracks-depend on the elastic properties of the vehicle, the hypothesis that it is possible to develop a simplified test track was verified by pointing out that:

- each channel had a very small range of frequencies of interest;

- the frequency bandwidth mainly affecting operator comfort changes when the considered axis varies $(x, y$ and $z)$.

The $\mathrm{x}$-axis presents two frequency ranges of interest: one from 0.6 to $1.2 \mathrm{~Hz}$ and another from 2 to $3.6 \mathrm{~Hz}$. These two groups indicate that there are two different kinds of solicitations affecting the operator: the first is related to the elastic parts' response to impulsive solicitation (i.e., passing a ditch, moving off with a trailer, manoeuvring during harrowing), while the second one is related to the vertical movement of the vehicle (as a matter of fact, the range from 2 to $3.6 \mathrm{~Hz}$ corresponds to the vertical resonance frequency of the tyres): the surface roughness induces a transformation of the horizontal component of the forward speed into vertical acceleration. At the same time, the y-axis 
also presents two ranges of interest: from 0.8 to $2 \mathrm{~Hz}$ and 3.2 to $3.8 \mathrm{~Hz}$. Of these, the first is the most interesting as the amplitude is related to the lateral movement of the tractor. In all the conditions, the z-channel turned out to be correlated to frequencies ranging from 2.2 to $3.4 \mathrm{~Hz}$, that is, the range of frequencies corresponding to the vertical resonance of the tyres.

If the combination between surface roughness and speed provides enough energy, the reaction of the elastic parts of the tractor-above all the tyres-plays a critical role in determining operator comfort.

These considerations confirmed the necessity to study the three orthogonal axes separately, opening up important issues about how these simplified test tracks could be further improved. The limit remains that it is necessary to carry out three tests, resulting in three different values that do not fit with the ultimate aim of obtaining an indication of tractor comfort with one index only.

\subsection{Defining a "Comfort Index"}

ISO 2631 [37] reports the most interesting parameter for representing vehicle comfort in one value: it recommends that, when assessing the effects on comfort, all the relevant vibration directions should be considered to obtain the overall total value of vibration:

$$
a_{w}=\left(\sum_{i} k_{i}^{2} a_{w i}^{2}\right)^{1 / 2}
$$

where:

- $\quad a_{w i}$ are weighted root mean square (rms) accelerations on the relevant axes;

- $k_{i}$ are multiplying factors.

The complete formula requires measurement of the acceleration along the 3 axes at the seat, back, feet, roll, pitch and yaw, for a total of 12 channels. It still needs to be clarified and further investigated if this equation fits for agricultural tractors, nevertheless it can be of great interest in building a simplified approach for parameter estimation.

\subsection{Defining the Machine Operating Conditions}

With reference to setting up the machine operating conditions, the test setting could follow the main recommendations of the ISO 5008 and ISO 2631 standards while rethinking their application within a simplified framework.

\section{Conclusions and Recommendations}

To allow test laboratories to measure performance characteristics, new standards have been developed as a result of the continuous restructuring of the agricultural machinery industry and the increasing complexity of agricultural and forestry tractors.

European Parliament and Council Directive 2002/44/EC on the exposure of workers to the risks arising from physical agents introduced, at the Community level, minimum protection requirements for workers when they are exposed to risks arising from vibration in the course of their work. It specifies employers' obligations with reference to risk identification and assessment, and it sets out the measures to be taken to reduce or avoid exposure and details how to provide information and training for workers. Any employer who intends to carry out work involving risks arising from exposure to vibration must implement a series of protection measures before and during the work. The Directive also requires EU Member States to put in place a suitable system for monitoring the health of workers exposed to risks arising from vibration.

The reduction of such risks must be based on general principles of prevention. Employers must establish and implement a programme of technical and/or organizational measures intended to reduce the exposure to mechanical vibration and its attendant risks to a minimum, taking into account the choice of suitable work equipment, the provision of auxiliary equipment reducing the risk of injuries caused by vibration (such as seats), the design and the layout of workplaces. 
Despite being conducted in controlled conditions (traversing ISO ride vibration test tracks; performing selected agricultural operations; performing identical tasks during "on-farm" use; transport on paved minor roads; developing focused and dedicated terrain or stony surfaces), the various studies presented herewith — carried out to quantify WBV emission and estimated exposure levels upon a range of agricultural tractors-suffer from a lack of comparability when the studied working conditions vary, with the exception of those carried out in accordance with ISO 5008.

While these studies confirmed that tractor WBV emission levels were found to be very dependent upon the nature of the operation performed, they have shown that changing soil profiles and tractor speeds give rise to similar spectral trends of the accelerations resulting from ground input. This result led researchers to investigate a possible and realistic simplification and standardization of the tractor driver comfort testing activity given the unpredictability of soil profile.

The literature presented in this review indicates the usefulness, and the possibility, of developing simplified procedures for measuring the exposure of agricultural tractor operators to WBV so that the outcome of the simplified procedure can be used to compare different tractors-provided that they belong to the same category-or a given tractor with different equipment (seats, suspension, tyres, etc.). Such simplified testing procedures cannot be considered suitable for determining operators' daily exposure to vibration in open field conditions.

Acknowledgments: The Organisation for Economic Co-operation and Development (OECD) Tractor Codes Programme commissioned this work: the opinions expressed and arguments are solely those of the authors and do not necessarily reflect the official views of the OECD or of its member countries. Authors are grateful to OECD delegates for the fruitful discussions during the OECD meetings.

Conflicts of Interest: The authors declare no conflict of interest. The founding sponsors had no role in the design of the study; in the collection, analyses, or interpretation of data; in the writing of the manuscript, or in the decision to publish the results.

\section{Appendix A. Standards}

- Directive 2002/44/EC of the European Parliament and of the Council of 25 June 2002 on the minimum health and safety requirements regarding the exposure of workers to the risks arising from physical agents (vibration). 2002.

- ISO-International Standard Organization (2002). Standard ISO 5008:2002. Agricultural wheeled tractors and field machinery-Measurement of whole-body vibration of the operator.

- BS 6841:1987 Guide to measurement and evaluation of human exposure to whole-body mechanical vibration and repeated shock. The British Standards Institution, London, UK.

- VDI 2057-1:2017-08. Human exposure to mechanical vibrations-Whole-body vibration. Beuth, Berlin, Germany.

- $\quad$ Leatherwood, J.D.; Barker, L.M. A User Oriented and Computerized Model for Estimating Vehicle Ride Quality. NASA Technical Paper 2299, April 1984.

- ISO-International Standard Organization (1997). Standard ISO 2631-1:1997. Mechanical vibration and shock-Evaluation of human exposure to whole-body vibration-Part 1: General requirements.

- EN-European Standard. EN 13059:2002+A1:2008. Safety of industrial trucks-Test methods for measuring vibration.

- ISO-International Standard Organization (1995). Standard ISO 8608:1995 mechanical vibrationRoad surface profiles-Reporting of measured data.

\section{References}

1. European Commission (EC). The Magnitude and Spectrum of Farm Injuries in the European Union Countries; European Commission (EC): Athens, Greece, 2004.

2. Health and Safety Authority (HSA). Farm Safety Action Plan 2013-2015, The Metropolitan Building 2013; Health and Safety Authority (HSA): Dublin, Germany, 2013. 
3. Litchfield, M.H. Agricultural Work Related Injury and Ill-Health and the Economic Cost. Environ. Sci. Pollut. Res. Int. 1999, 6, 175-182. [CrossRef] [PubMed]

4. Hoy, D.; Brooks, P.; Blyth, F.; Buchbinder, R. The Epidemiology of low back pain. Best 426. Pract. Res. Clin. Rheumatol. 2010, 24, 769-781. [CrossRef] [PubMed]

5. Monarca, D.; Porceddu, P.; Cecchini, M.; Babucci, V. Microclimate risk evaluation in agroindustrial work environments. Riv. Ing. Agrar. 2005, 4, 89-93.

6. Di Giacinto, S.; Colantoni, A.; Cecchini, M.; Monarca, D.; Moscetti, R.; Massantini, R. Dairy production in restricted environment and safety for the workers. Ind. Aliment. 2012, 51, 5-12.

7. Monarca, D.; Cecchini, M.; Guerrieri, M.; Santi, M.; Bedini, R.; Colantoni, A. Safety and health of workers: Exposure to dust, noise and vibrations. Acta Hortic. 2009, 845, 437-442. [CrossRef]

8. Okunribido, O.O.; Magnusson, M.; Pope, M.H. Low back pain in drivers: The relative role of whole body vibration, posture and manual materials handling. J. Sound Vib. 2006, 298, 540-555. [CrossRef]

9. Chiang, C.F.; Liang, C.C. A study on biodynamic models of seating human subjects exposed to vertical vibration. Int. J. Ind. Ergon. 2006, 36, 869-890.

10. Seidel, H.; Heide, R. Long-term effects of whole-body vibration: A critical survey of the literature. Int. Arch. Occup. Environ. Health 1986, 58, 1-26. [CrossRef] [PubMed]

11. Bonghers, P.; Boshuizen, H. Back Disorders and Whole-Body Vibrations at Work. Ph.D. Thesis, L'universite d'Amsterdam, Den Haag, The Netherland, October 1990.

12. Manetto, G.; Cerruto, E. Vibration risk evaluation in hand-held harvesters for olives. J. Agric. Eng. 2013, 44, 705-709. [CrossRef]

13. Lenzuni, P.; Deboli, R.; Preti, C.; Calvo, A. A round robin test fot the hand-transmitted vibration from an olive harvester. Int. J. Ind. Ergon. 2016, 53, 86-92. [CrossRef]

14. Bovenzi, M. Exposure-response relationship in the hand-arm vibration syndrome: An overview of current epidemiology research. Int. Arch. Occup. Environ. Health 1998, 7, 509-519. [CrossRef]

15. Bovenzi, M. Health effects of mechanical vibration. G Ital. Med. Lav. Ergon. 2005, 27, 58-64. [PubMed]

16. Punnett, L.; Wegman, D.H. Work-related musculoskeletal disorders: The epidemiologic evidence and the debate. J. Electromyogr. Kinesiol. 2004, 14, 13-23. [CrossRef] [PubMed]

17. Bishu, R.R.; Chen, Y.; Cochran, D.J.; Riley, M.W. Back injuries in farming-A pilot investigation. In Advances in Industrial Ergonomics and Safety, Proceedings of the Annual International Industrial Ergonomics and Safety Conference, Cincinnati, OH, USA, 5-9 June 1989; Taylor \& Francis: Abingdon-on-Thames, UK, 1989; pp. 791-798.

18. European Parliament. Directive 2002/44/EC of the European Parliament and of the Council of 25 June 2002 on the Minimum Health and Safety Requirements Regarding the Exposure of Workers to the Risks Arising from Physical Agents (Vibration); European Agency for Safety and Health at Work: Bilbao, Spain, 2002.

19. International Standard Organization (ISO). Agricultural Wheeled Tractors and Field Machinery-Measurement of Whole-Body Vibration of the Operator; Standard ISO 5008:2002; International Standard Organization (ISO): Geneva, Switzerland, 2002.

20. European Agency for Safety and Health at Work. 2005-Expert Forecast on Emerging Physical Risks Related to Occupational Safety and Health; European Agency for Safety and Health at Work: Bilbao, Espana, 2005; ISBN 92-9191-165-8.

21. Cecchini, M.; Colantoni, A.; Monarca, D.; Longo, L.; Riccioni, S. Reducing the risk from manual handling of loads in agriculture: Proposal and assessment of easily achievable preventive measures. Chem. Eng. Trans. 2017, 58, 85-90.

22. Health and Safety Executive (HSE). Control Back-Pain Risks from Whole-Body Vibration Advice for Employers on the Control of Vibration at Work Regulations 2005; Health and Safety Excutive (HSE): Liverpool, UK, 2005; HSE Books; ISBN 0-7176-6119-9. Available online: www.hse.gov.uk/pubns/indg242.pdf (accessed on 9 January 2017).

23. Barriera-Viruet, H.; Genaidy, A.; Shell, R.; Salem, S.; Karwowski, W. Effect of forklift operation on lower back pain: An evidence-based approach. Hum. Factors Ergon. Manuf. 2008, 18, 125-151. [CrossRef]

24. Lings, S.; Leboeuf-Yde, C. Whole body vibration and low back pain: A sistematic, critical review of the epidemiologiacal literature 1992-1999. Int. Arch. Occup. Environ. Health 2000, 73, 290-297. [CrossRef] [PubMed] 
25. Bovenzi, M.; Betta, A. Low-back disorders in agricultural tractor drivers exposed to whole-body vibration and postural stress. Appl. Ergon. 1994, 25, 231-241. [CrossRef]

26. Lötters, F.; Burdorf, A.; Kuiper, J.; Miedema, H. Model for the workrelatedness of low-back pain. Scand. J. Work Environ. Health 2003, 29, 431-440. [CrossRef] [PubMed]

27. Laštovková, A.; Nakládalová, M.; Fenclová, Z.; Urban, P.; Gaourek, P.; Lebeda, T.; Ehler, E.; Ridzoň, P.; Hlávková, J.; Boriková, A.; et al. Low-back pain disorders as occupational diseases in the Czech Republic and 22 European Countries: Comparison of national systems, related diagnoses and evaluation criteria. Cent. Eur. J. Public Health 2015, 23, 244-251. [CrossRef] [PubMed]

28. Hulshof, C.T.J.; Van der Laan, G.; Braam, I.T.J. The fate of Mrs Robinson: Criteria for recognition of whole body vibration injury as an occupational disease. J. Sound Vib. 2002, 253, 185-194. [CrossRef]

29. Health and Safety Executive (HSE). Whole-Body Vibration in Agriculture, Agriculture Information Sheet No 20 (Revision 2); Health and Safety Excutive (HSE): Liverpool, UK, 2013. Available online: www.hse.gov.uk/ pubns / ais20.htm (accessed on 9 January 2017).

30. Ente Nazionale Per La Meccanizzazione Agricola (ENAMA). Produzione Documentale Tecnica Sulla Problematica Delle Vibrazioni Connessa All'uso Delle Macchine Agricole; Ente Nazionale Per La Meccanizzazione Agricola (ENAMA): Roma, Italy, 2005.

31. European Agricultural Machinery (CEMA). Whole-body vibration in agriculture. In Practical User's Guide; European Agricultural Machinery (CEMA): Brussel, Belgium, 2005.

32. European Union (EU). Guide to Good Practice on Whole-Body Vibration; European Union (EU): Brussel, Belgium, 2006.

33. Els, P.S. The applicability of ride comfort standards to off-road vehicles. J. Terramech. 2005, 42, 47-64. [CrossRef]

34. Guide to Measurement and Evaluation of Human Exposure to Whole-Body Mechanical Vibration and Repeated Shock; The British Standards Institution: London, UK, 1987; BS 6841:1987.

35. Human Exposure to Mechanical Vibrations-Whole-Body Vibration; VDI 2057-1:2017-08; Beuth: Berlin, Germany, 2017.

36. Leatherwood, J.D.; Barker, L.M. A User Oriented and Computerized Model for Estimating Vehicle Ride Quality; NASA Technical Paper 2299; Scientific and Technical Information: Washington, DC, WA, USA, 1984.

37. International Standard Organization (ISO). Mechanical Vibration and Shock-Evaluation of Human Exposure to Whole-Body Vibration - Part 1: GENERAL Requirements; Standard ISO 2631-1:1997; International Standard Organization (ISO): Geneva, Switzerland, 1997.

38. Paschold, W.E. Whole Body Vibration Knowledge Gaps in the US. In Proceedings of the Third American Conference on Human Vibration, Iowa City, IA, USA, 1-4 June 2010. [CrossRef]

39. PAF. Available online: http://www.portaleagentifisici.it/fo_wbv_list_macchinari_avanzata.php?lg=IT\& page $=0$ (accessed on 8 May 2017).

40. Pacejka, H.B. Tyre and Vehicle Dynamics, 2nd ed.; Butterworth Heinemann: Oxford, UK, 2010.

41. Taylor, R.K.; Bashford, L.L.; Schrock, M.D. Methods for measuring vertical tire stiffness. Trans. ASABE 2000, 4343, 1415-1419. [CrossRef]

42. Crolla, D.A. Off-Road Vehicle Dynamics. Veh. Syst. Dyn. 1981, 10, 253-266. [CrossRef]

43. Previati, G.; Gobbi, M.; Mastinu, G. Farm tractor models for research and development purposes. Veh. Syst. Dyn. 2007, 45, 37-60. [CrossRef]

44. Wille, R.; Bohm, F.; Duda, A. Calculation of the rolling contact between a tyre and deformable ground. Veh. Syst. Dyn. 2005, 43 (Suppl. 1), 483-492. [CrossRef]

45. Kabir, M.S.N.; Ryu, M.J.; Chung, S.O.; Kim, Y.J.; Choi, C.H.; Hong, S.J.; Sung, J.H. Research Trends for Performance, Safety, and Comfort Evaluation of Agricultural Tractors: A Review. J. Biosyst. Eng. 2014, 39, 21-33. [CrossRef]

46. Pazooki, A.; Cao, D.; Rakheja, S.; Boileau, P.E. Ride dynamic evaluations and design optimization of a torsio-elastic off-road vehicle suspension. Veh. Syst. Dyn. 2011, 49, 1455-1476. [CrossRef]

47. Braghin, F.; Cheli, F.; Genoese, A.; Sabbioni, E.; Bisaglia, C.; Cutini, M. Experimental modal analysis and numerical modelling of agricultural vehicles. In Proceedings of the IMAC-XXVII A Conference and Exposition on Structural Dynamics, Orlando, FL, USA, 9-12 February 2009.

48. Oude Vrielink, H.H.E. Comparison of High Power Agricultural Tractors: Effect on Whole Body Vibration Exposure during a Standardized Test in Practice; Ergolab Research B.V.: Bennekom, The Nederland, 2012. 
49. Scarlett, A.J.; Price, J.S.; Stayner, R.M. Whole body vibration: Evaluation of emissions and exposure levels arising from agricultural tractors. J. Terramech. 2007, 44, 65-73. [CrossRef]

50. Deboli, R.; Calvo, A.; Preti, C. Comparison between ISO 5008 and Field Whole Body Vibration Tractor Values. J. Agric. Eng. 2012, 43. [CrossRef]

51. European Committee for Standardization. Safety of Industrial Trucks-Test Methods for Measuring Vibration; UNI-EN 13059:2002+A1:2008; European Committee for Standardization: Milan, Italy, 2002.

52. Nguyen, V.N.; Inaba, S. Effects of tire inflation pressure and tractor velocity on dynamic wheel load and rear axle vibrations. J. Terramech. 2011, 48, 3-16. [CrossRef]

53. International Standard Organization (ISO). Mechanical Vibration_Road Surface Profiles_Reporting of Measured Data; Standard ISO 8608:1995; International Standard Organization (ISO): Geneva, Switzerland, 1995.

54. Roman, L.; Florea, A.; Cofaru, I.I. Software Application for assessment the reliability of suspension system at Opel cars and of road profiles. Fascicle Manag. Technol. Eng. 2014, 1, 289-294. [CrossRef]

55. Agostinacchio, M.; Ciampa, D.; Olita, S. The vibrations induced by surface irregularities in road pavements-A Matlab approach. In European Transport. Research Review, 2013th ed.; Springer: Berlin/Heidelberg, Germany, 2013.

56. Park, S.; Popov, A.A.; Cole, D.J. Influence of soil deformation on off-road heavy vehicle suspension vibration. J. Terramech. 2004, 441, 41-68. [CrossRef]

57. González, A.; O'brien, E.J.; Li, Y.Y.; Cashell, K. The use of vehicle acceleration measurements to estimate road roughness. Veh. Syst. Dyn. 2008, 46, 483-499. [CrossRef]

58. Fassbender, F.R.; Fervers, C.W.; Harnisch, C. Approaches to predict the vehicle dynamics on soft soil. Veh. Syst. Dyn. 1997, 27, 173-188. [CrossRef]

59. Bisaglia, C.; Cutini, M.; Gruppo, G. Assessment of vibration reproducibility on agricultural tractors by a "four poster test stand". In Proceedings of the XVI CIGR. EurAgEng 2006 64th VDI-MEG and FAO joint “World Congress-Agricultural Engineering for a Better World", Bonn, Germany, 3-7 September 2006.

60. Anthonis, J.; Vaes, D.; Engelen, K.; Ramon, H.; Swevers, J. Feedback Approach for Reproduction of Field Measurements on a Hydraulic Four Poster. Biosyst. Eng. 2007, 96, 435-445. [CrossRef]

61. Cutini, M.; Bisaglia, C.; Bertinotti, S.A. Power spectral analysis of agricultural field surface. In Proceedings of the XVII World Congress of the International Commission of Agricultural and Biosystem. Engineering, Quebec, QC, Canada, 13-17 June 2010.

62. Cutini, M.; Deboli, R.; Calvo, A.; Preti, C.; Inserillo, M.; Bisaglia, C. Spectral analysis of a standard test track profile during passage of an agricultural tractor. J. Agric. Eng. 2013, 44 (Suppl. 1), 719-723. [CrossRef]

63. Cutini, M.; Bisaglia, C. Procedure and layout for the development of a fatigue test on an agricultural implement by a four poster test bench. J. Agric. Eng. 2013, 44, 402-405. [CrossRef]

64. Cutini, M.; Bisaglia, C. Experimental identification of a representative soil profile to investigate Tractor Operator's Discomfort and Material Fatigue Resistance. In Proceedings of the International Conference of Agricultural Engineering (AgEng 2014 Zurich), Zurich, Switzerland, 6-10 July 2004; p. 8.

65. Jianmin, G.; Gall, R.; Zuomin, W. Dynamic Damping and Stiffness Characteristics of the Rolling Tire. Tire Sci. Technol. 2001, 29, 258-268. [CrossRef]

66. Cutini, M.; Deboli, R.; Calvo, A.; Preti, C.; Brambilla, M.; Bisaglia, C. Ground Soil Input Characteristics Determining Agricultural Tractor Dynamics. Appl. Eng. Agric. 2017, 33. [CrossRef]

67. Gobbi, M.; Mastinu, G.; Pennati, M.; Previati, G. Farm tractor ride comfort assessment. In The Dynamics of Vehicles on Roads and Tracks; Resenberger, M., Plochi, M., Klaus, S., Edelmann, J., Eds.; Taylor \& Francis Group: London, UK, 2016; pp. 125-136, ISBN 978-1-138-02885-2.

68. Cutini, M.; Costa, C.; Bisaglia, C. Development of a simplified method for evaluating agricultural tractor's operator whole body vibration. J. Terramech. 2016, 63, 23-32. [CrossRef]

(C) 2017 by the authors. Licensee MDPI, Basel, Switzerland. This article is an open access article distributed under the terms and conditions of the Creative Commons Attribution (CC BY) license (http:/ / creativecommons.org/licenses/by/4.0/). 